Discussion Paper No. 01-60

\title{
A Mean Variance King? \\ Creation and Resolution of Uncertainty Under the Employment Report's Reign
}

Nikolaus Hautsch and Dieter Hess

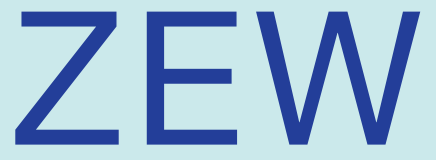

Zentrum für Europäische Wirtschaftsforschung GmbH

Centre for European

Economic Research 



\section{Non-Technical Summary}

This paper analyzes the impact of unexpected information in the US employment report on T-Bond futures. Information arrival can have two effects: On the one hand, non-anticipated information in public news induces a shift in traders' beliefs about the equilibrium price level. On the other hand, the implications of new macroeconomic information may be interpreted differently across traders leading to an increase in volatility. In contrast to the previous literature which has studied the impact on the level of prices and on the volatility of prices separately, we model both effects simultaneously.

This simultaneous estimation approach allows us to gain some interesting insights into the processing of information. Non-anticipated information leads to a sharp and consistent price reaction suggesting that traders' average believes shift almost instantaneously. Nevertheless, after controlling for the effect on the mean we still find a strong and persistent increase in volatility which points to considerable disagreement among traders about the precise implications of macroeconomic news. These differences of opinion about the new equilibrium price are resolved only slowly.

Furthermore, we delineate the different modes of impact of non-anticipated information on volatility: We find that traders' uncertainty increases with the magnitude of surprises. 'Bad' news irritate traders considerably more than 'good' news. Surprises in similar headline figures pointing into the same direction 're-enforce' the price signal. Hence, leaving less room for differences of opinion, volatility is found to be decreased after such signals. 



\title{
A mean variance king? Creation and resolution of uncertainty under the employment report's reign *
}

\author{
Nikolaus Hautsch ${ }^{\dagger}$ \\ Dieter Hess ${ }^{\ddagger}$ \\ Center of Finance and Econometrics (CoFE) \\ University of Konstanz, D-78457 Konstanz, Germany
}

July 2001

\begin{abstract}
This paper delineates the simultaneous impact of non-anticipated information on first and second moments of the intraday price process by including appropriate variables accounting for the news flow into both the mean and the variance function. This allows us to differentiate between the consistent price reaction to surprising news and traders' uncertainty about the precise price impact of this information. Analyzing the US employment report, we find that headline information is almost instantaneously incorporated into T-bond futures prices. Nevertheless, large surprises create considerable uncertainty, in particular 'bad' news. In contrast, if surprises in related headlines cross-validate each other, less room for differences of opinion is left, and hence volatility is decreased.
\end{abstract}

Keywords: $\quad$ Information processing; trading process; volatility; macroeconomic announcements; Treasury bond futures; high-frequency data

JEL classification: E44, G14

*For valuable comments we are grateful to Ben Craig, Günter Franke, Stefan Klotz, Michael Lechner, Winfried Pohlmeier, and Harris Schlesinger. This paper has also strongly benefited from comments of workshop participants at the Universities of Konstanz and St. Gallen. Data on analysts' forecasts were generously provided by Standard \& Poors Global Markets. The authors gratefully acknowledge financial support by the Deutsche Forschungsgemeinschaft (DFG) within the Center of Finance and Econometrics (CoFE). Dieter Hess appreciates a grant by the DFG (project HE 3180/1).

†Tel: +49 7531 882204, e-mail: nikolaus.hautsch@uni-konstanz.de

‡Tel: +497531 883164, e-mail: dieter.hess@uni-konstanz.de 


\section{Introduction}

This paper investigates the processing of macroeconomic news in financial markets, in particular surprises in headline figures of the US employment report. We model simultaneously two effects of public news arrival: On the one hand, non-anticipated information in public news induces a shift in traders' beliefs about the equilibrium price level which should result in a sharp and immediate price reaction. While average beliefs shift instantaneously, on the other hand, traders do not have to agree about the precise price impact of a given piece of information. Uncertainty about the new equilibrium price level causes prices to fluctuate more widely around the new equilibrium level until a new consensus is reached. We disentangle these effects by controlling for the impact of non-anticipated information on both the mean and the variance function. Instead of focussing on forecasts of the variance of returns after controlling for some seasonalities in signed returns, we model traders' uncertainty about the precise price impact of new information while controlling for the shift in traders' beliefs.

From the previous literature it is well known that information arrival has an impact on both prices and volatility in financial markets (see e.g., Goodhart and O'Hara 1997 for an overview). ${ }^{1}$ Nevertheless, previous empirical studies on announcement effects have either focused on the impact of scheduled announcements on signed returns (e.g. Berkman 1978, Urich and Wachtel 1984, Hardouvelis 1988, Fleming and Remolona 1997, and Hess 2001) or on the volatility of returns (e.g. Harvey and Huang 1991, Ederington and Lee 1993, Fleming and Remolona 1999a, and Franke

\footnotetext{
${ }^{1}$ There is also some tradition using volatility as a proxy for information arrival. See, e.g. Lamoureux and Lastrapes (1990) or Franke and Hess (2000b).
} 
and Hess 2000a) neglecting relations between the impact of non-anticipated information on first and second moments. ${ }^{2}$ We close this apparent gap of the literature by modelling the impact of announcements on both the mean and variance function simultaneously. Our approach provides some interesting insights into the processing of information. It enables us to distinguish between a volatility shock arising from a news induced shift of the price to a new equilibrium and a situation in which prices are just bouncing around, for example, because traders' opinions diverge largely. Non-anticipated information leads to a sharp and consistent price reaction suggesting that traders' average beliefs shift almost instantaneously. Nevertheless, after controlling for the effect on the mean we still find a strong and persistent increase in volatility which points to considerable disagreement among traders about the precise implications of macroeconomic news. These differences of opinion are resolved only slowly.

We use high-frequency data of the Chicago Board of Trade (CBOT) T-bond future in order to investigate the effects of news arrival. One problem in this context is the simultaneous occurrence of releases. To avoid an interference of effects caused by multiple releases, in this study only one announcement is used, but a very important one, i.e. the employment report. ${ }^{3}$ Besides being the most influential report, it has the nice property that the overlap with other announcements is minimal. During the five-year sample used here, i.e. January 1995 to December 1999, only 7 out of the 60

\footnotetext{
${ }^{2}$ Note that a few studies investigate both signed returns and absolute returns, as well as some other variables such as trading volume or bid-ask spreads. For example, Fleming and Remolona (1997) run separate regressions of signed returns on surprises as well as absolute returns and trading volume on announcement dummies and absolute surprises. See also Balduzzi, Elton, and Green (1997). Nevertheless, these studies do not model the simultaneous impact of announcements on first and second moments.

${ }^{3}$ Several studies document that the employment report has by far the highest impact on the mean function (e.g. Balduzzi, Elton, and Green 1997, Hess 2001) as well as the variance function (Ederington and Lee 1993, Fleming and Remolona 1997).
} 
employment announcement days are lost due to an announcement of other releases at the same time, i.e. 8:30 a.m. ET. ${ }^{4}$ In order to keep the results free from the influence of announcements made at 10:00 a.m. on some of the employment report days, we focus on a 90-minute window in which information processing should be driven almost completely by the employment release.

The effects of information arrival are analyzed by means of an intraday ARCH model with multiplicative heteroscedasticity on 2-min returns. Explanatory variables which capture the time pattern and the impact of surprises are included in the mean function as well as in the variance specification. In order to analyze the explanatory power of the different model components their predictive performance is evaluated separately. This allows us to differentiate between the explanatory power of the implemented ARCH component, the variables capturing deterministic time patterns, and the additional explanatory variables, i.e. surprises in headline figures.

Based on this estimation approach, we provide several contributions to the previous literature. In particular, we disentangle the simultaneous impact of information arrival on first and second moments of the return process. Furthermore, we delineate the different modes of impact of non-anticipated information on volatility: absolute effects, asymmetric impacts, and a 're-enforcement' effect. We provide some evidence that traders' differences of opinion increase with the magnitude of a surprise. 'Bad' news irritate traders considerably more than 'good' news. Surprises in similar headline figures pointing into the same direction 're-enforce' the price signal, and thus leave less room for differences of opinion.

The remainder of this paper is organized as follows. The subsequent section reviews

\footnotetext{
${ }^{4}$ This includes an inadvertently early release of the November 1998 employment report. See Fleming and Remolona (1997).
} 
briefly the related literature. Section 3 characterizes the major information components in the employment report. Moreover, several hypotheses are derived concerning the processing of outstanding information. Section 4 describes the data, explains the estimation procedure, and presents the empirical results. Section 5 concludes.

\section{Previous studies - a synthesis}

The previous literature on announcement effects can be divided into two branches, one focussing on first moments, the other one on second moments. The first branch analyzes the signed price impact of non-anticipated information. The main question of this literature is which types of announcements significantly affect the equilibrium price level. Usually, these studies measure the magnitude of surprises employing survey data on analysts' forecasts for certain headline figures contained in macroeconomic reports. Non-anticipated information is then measured by the deviation of a given headline figure $\left(A_{\tau}\right)$ announced at time $\tau$ from the median of analysts' forecasts $\left(F_{\tau}\right)$. Hence, the surprise in the $i$ th headline figure is given as $S_{i, \tau}=A_{i, \tau}-F_{i, \tau}$.

Typically, the impact on the return in period $t$ is investigated by regressing signed $\log$ returns $r_{t}$ on surprises in some set of macroeconomic announcements $(i=1, \ldots, n)$, i.e.

$$
r_{t}=\alpha_{0}+\sum_{i=1}^{n} \alpha_{i} S_{i, \tau} D_{i, t=\tau}+\varepsilon_{t},
$$

where $D_{i, t=\tau}$ denotes headline specific dummy variables which take on the value 1 if announcement $i$ is made during the interval $t$, and 0 else. In addition, lagged returns or terms controlling for seasonalities in returns such as day-of-the-week effects may be included in such an analysis. ${ }^{5}$ Heteroscedasticity in the error term $\varepsilon_{t}$ is usually

\footnotetext{
${ }^{5}$ See, for example, Fleming and Remolona (1997) or Hess (2001).
} 
not explicitly modelled. Instead, some heteroscedasticity consistent estimator for the variance-covariance matrix is applied.

Early studies investigate the impact of announcements on daily returns. For example, Berkman (1978), and Urich and Wachtel $(1981,1984)$ analyze money growth announcements, Cook and Korn (1991) and Prag (1994) focus on employment reports. After the Federal Reserve deemphasized monetary aggregates to guide its policy actions in the early 1980s, Hardouvelis (1988), Dwyer and Hafer (1989), and Edison (1996), among others, find a growing influence of employment figures, releases of consumer and producer prices, durable goods orders and retail sales. While these studies examine daily data, mainly from bond markets, Becker, Finnerty, and Kopecky (1996), Fleming and Remolona (1997, 1999b), and Hess (2001) focus on narrow intraday windows around the announcements in order to separate the impact of scheduled announcements from other not explicitly observed news which may arrive occasionally over the course of a trading day. As a consequence, these studies find that more types of announcements have a significant impact on bond prices. Overall, studies on first moments suggest a significant and immediate adjustment of the level of prices to non-anticipated information. In particular, surprising information in the employment report triggers the most pronounced price responses.

A second branch of the literature on announcement effects analyzes volatility shocks. First of all, these studies show that scheduled macroeconomic announcements stand out from the steady flow of information which hits financial markets. Fleming and Remolona (1997) find that out of the 25 largest intraday price changes in the U.S. treasury market all but one occurred after such an announcement, in particular, after employment reports. This is confirmed by Bollerslev, Cai, and Song (2000) for 
T-bond futures, and Dominguez (1999) obtains similar results for DEM/USD spot rate. ${ }^{6}$ In contrast to studies on first moments, the literature on second moments usually does not account for surprises in releases. In general, the impact of the mere existence of an announcement is investigated, for example, by regressing absolute $\log$ returns, $\left|r_{t}\right|$, on the above defined dummy variables which account for the timing of announcements only, i.e. ${ }^{7}$

$$
\left|r_{t}\right|=\alpha_{0}+\sum_{i=1}^{n} \alpha_{i} D_{i, t=\tau}+\nu_{t}
$$

Constructing such dummy variables from the schedule of macroeconomic releases Harvey and Huang (1991), Ederington and Lee (1993), Crain and Lee (1995), Franke and Hess (2000a), and others document that quite a number of different types of releases have a significant impact on (intraday) volatility, mainly in bond and foreign exchange markets.

The persistence of volatility after such an announcement is another issue which has gained widespread attention. Ederington and Lee (1993), for example, analyze the sample variance in 5-minute intervals across announcement days and find that volatility is significantly higher in the interval associated with the announcement and that it declines rapidly afterwards. This is confirmed for several markets by various other studies (e.g. Ederington and Lee 1995, Crain and Lee 1995, Balduzzi, Elton, and Green 1997, Fleming and Remolona 1999a, and Franke and Hess 2000a). Most intraday studies suggest that the volatility shock is only short-lived. Volatility seems to persist somewhat longer in more liquid instruments (Christie-David and

\footnotetext{
${ }^{6}$ However, it is not clear whether these findings are due to consistent price reactions to new information or just volatility shocks.

${ }^{7}$ See, for example, Ederington and Lee (1993) or Fleming and Remolona (1997). In general, seasonalities in volatilities such as day-of-week or time-of-the-day effects are controlled for by including appropriately defined additional dummy variables.
} 
Chaudhry 1999).

Based on the framework of Andersen and Bollerslev (1997), Bollerslev, Cai, and Song (2000) investigate intraday seasonal patterns in volatility after controlling for interday GARCH effects. On the basis of a switching GARCH model, Jones, Lamont, and Lumsdaine (1998) as well as Jones (1998) find no significantly higher interday volatility persistence after the release of the employment report and the producer price index. In contrast, disentangling dynamic GARCH effects and announcement effects, Li and Engle (1998) are able to reject the hypothesis that volatility persistence from announcement days is the same as from non-announcement days. Moreover, they present evidence in favor of the "calm before the storm" effect, i.e. that volatility on pre-announcement days is significantly reduced. Li and Engle estimate a filtered GARCH model which in its simplest form can be written as

$$
\begin{aligned}
r_{t} & =c+f_{t} \varepsilon_{t} \\
h_{t} & =\omega+\alpha \varepsilon_{t-1}^{2}+\beta h_{t-1}+\gamma \varepsilon_{t-1}^{2} I_{\varepsilon_{t-1}<0} \\
f_{t} & =f\left(D_{t}, W_{t}\right)
\end{aligned}
$$

with $\varepsilon_{t}=h_{t} u_{t}$ and $u_{t} \sim N(0,1)$. Here, announcement day dummies $\left(D_{t}\right)$ and dayof-the-week dummies $\left(W_{t}\right)$ enter the filter $f_{t}$, not the GARCH equation $h_{t} . I_{\varepsilon_{t-1}<0}$ is an indicator variable taking on the value 1 for a negative $\varepsilon_{t-1}$ and zero else. Hence this approach allows to account for asymmetric ARCH effects. Li and Engle also test for the impact of 'bad' news in announcements on the persistence of volatility by augmenting the GARCH equation with appropriate indicator variables. 'Bad' news, however, is not measured by the sign of surprises in individual headline figures (i.e. $S_{t}=F_{t}-A_{t}$ ) like in studies on first moments. Instead, the sign of the announcement day's return is used to assess whether a release provided 'good' or 'bad' news 
(i.e. $\left.I_{\varepsilon_{t-1}<0}\right)$. Li and Engle find that the conditional volatility on post-announcement days is significantly higher when a negative return on the announcement day was observed, i.e. when 'bad' news occurred.

Overall, studies on second moments do not account for the consistent price reaction to non-anticipated information arrival which is well documented by studies on first moments. Usually second moments studies are concerned with volatility forecasting, mainly from a pre-announcements perspective. Hence only information available before an announcement is regarded to be relevant. However, an important questions is whether the observed volatility spike after macroeconomic announcements is just due to a news induced jump of the price to a new equilibrium level.

Therefore, we control for the price impact of non-anticipated information by including appropriate news flow variables into the mean function. Let $r_{t}$ denote the 2 -minute $\log$ return associated with the interval $t$, with $t=1, \ldots, T$. Then, the mean function of $r_{t}$ is modelled as

$$
r_{t}=x_{t}^{\prime} \beta+\epsilon_{t}, \quad \epsilon_{t}=u_{t} \sigma_{t}, \quad u_{t} \sim N(0,1)
$$

where $\beta$ is a coefficient vector and $x_{t}$ denotes the corresponding vector of explanatory variables. Note that $x_{t}$ includes a constant as well as surprises in individual headline figures (see section 4 for more details on the specific definition of variables).

We investigate the creation of uncertainty about the precise price impact of new information. Hence we model the variance of $\epsilon_{t}$, i.e. $\sigma_{t}^{2}\left(\epsilon_{t}\right)=\sigma_{t}^{2}$, rather than the variance of (centered) returns, $r_{t}-c$. Including also information variables into the vector of explanatory variables $w_{t}$ which enter the variance specification

$$
\sigma_{t}^{2}=\phi \epsilon_{t-1}^{2}+\exp \left(w_{t}^{\prime} \gamma\right)
$$


allows us to study the impact of new information on traders' uncertainty. In particular, $w_{t}$ includes absolute surprises as well as signed surprises in the individual headline figures of the employment report (see section 4 for more details). Note that $w_{t}$ includes a constant term. $\gamma$ is the corresponding coefficient vector. Estimating equations (1) and (2) simultaneously, our approach may be viewed as a synthesis of the previous literature on first and second moments.

\section{Information diffusion in efficient markets}

What is it that makes markets react so sharply to macroeconomic announcements? How does the price adjustment process to non-anticipated information work? In order to analyze these and other questions, first the information content of the major headline figures of an employment report is described. Hypotheses concerning the impact of this information on the mean and variance of returns are presented thereafter.

\subsection{The information content of the employment report}

Several studies have documented that the monthly report on the U.S. employment situation prepared by the Bureau of Labor Statistics (BLS) is the most influential macroeconomic release for financial markets. ${ }^{8}$ Its importance stems from the fact that it is an extremely timely and comprehensive measure of economic activity. Nonfarm payroll employment, for example, is commonly seen as a coincident indicator

\footnotetext{
${ }^{8}$ See, for example, Bollerslev, Cai, and Song (2000) or Fleming and Remolona (1999a) for its impact on intraday volatility and Fleming and Remolona (1997) or Hess (2001) for its intraday price impact. Nevertheless, on the basis of daily data Li and Engle (1998), for example, only find an insignificantly higher impact and an insignificantly stronger persistence of this report.
} 
of the business cycles. ${ }^{9}$ Moreover, both payroll employment as well as the unemployment rate provide a measure of the tightness of the labor market and thus an indication of price pressures in probably the most important input factor, i.e labor.

The employment report is a rather voluminous document containing quite an amount of detail information. This is one reason why previous studies have focused on headline figures which summarize this information. Another reason is the availability of so-called consensus forecasts of these figures which allow to measure the nonanticipated part of information arrival. While some studies present evidence that analysts' forecasts of macroeconomic figures are not always unbiased and efficient, test results are rather instable across different sample periods. For example, it is hard to detect stable autocorrelation patterns in analysts' forecasts errors. On the other hand, the forecast performance of analysts is particularly low for reports being announced early in the release cycle, as it is the case with the employment report. ${ }^{10}$ Previous studies of the employment report restrict their attention to two headline figures, the nonfarm payroll measure and the unemployment rate. For example, Hardouvelis (1988), Dwyer and Hafer (1989) and Prag (1994) analyze surprises in unemployment rates, while Fleming and Remolona (1997) use nonfarm payrolls. Some authors employ both nonfarm payrolls and unemployment rates, for example, Cook and Korn (1991), Edison (1996), Balduzzi, Elton, and Green (1997), and Hess (2001). However, none of these studies uses the hourly earnings figure. ${ }^{11}$ In this paper, all three aforementioned headline figures are analyzed, i.e. nonfarm payrolls,

\footnotetext{
${ }^{9}$ See, for example Rogers (1998, ch. 1).

${ }^{10} \mathrm{As}$ a comparison of the standard deviation of changes in announced headline figures and analysts' forecast errors reveals, analysts are not able to reduce the uncertainty of market participants for any of the three employment headline series. See, e.g. Hess and Moersch (2001).

${ }^{11}$ Probably due to the fact that most survey agencies did not collect forecasts for this headline figure before 1995 .
} 
unemployment rates, and average hourly earnings. ${ }^{12}$

Payroll employment as well as the unemployment rate provide market participants with several indications about current economic conditions. Both figures are measures of overall economic activity. In addition, both are commonly seen to be an indicator of consumers' spending power. Moreover, they provide an indication of price pressures arising from the labor market. No matter what interpretation market participants might like best, note that the information content of payrolls and (un)employment rates is strongly related. Therefore, it may be argued that using one of these figures is enough to capture most of the information. However, although they show similar fluctuations over the long run, both are derived from different sources. While the unemployment rate figure is derived from the household survey, the payroll measure (like hourly earnings) is based on the much larger establishment survey. ${ }^{13}$ Hence, over the short term they can move into opposite directions. One argument that market participants consider the nonfarm payroll figure to be more important, is that changes in nonfarm payrolls are less volatile than changes in unemployment rates. ${ }^{14}$

As mentioned above, financial markets also try to infer from employment figures whether inflationary pressures are building up which may arise from an increased bargaining power of employees in a tight labor market. A related but more direct

\footnotetext{
${ }^{12} \mathrm{~A}$ fourth headline figure which receives attention from time to time is the average workweek, i.e. the average number of hours worked. This measure is not employed here since MMS does not provide survey data for this figure before October 1998. Hence, only a few data points are available.

${ }^{13}$ The unemployment rate figure counts civilian noninstitutional employees including agricultural workers as well as self-employed persons. In contrast, nonfarm payrolls measure the number of jobs added in nonagricultural industries. Double-counting from persons who hold multiple jobs is not avoided. See, for example, Rogers (1998) ch. 1, or Niemira and Zukowski (1998) ch. 10.

${ }^{14} \mathrm{In}$ fact, during our sample period the standard deviation of relative month-over-month changes in nonfarm payrolls turns out to be $0.119 \%$, in unemployment rates $0.161 \%$, and in hourly earnings $0.244 \%$. See also Hess and Moersch (2001).
} 
information is obtained from average hourly earnings. Obviously, this figure provides a straightforward reading of price changes in the input factor labor. However, while hourly earnings primarily measure current price pressures, trends in employment may allow market participants to foresee wage increases down the road. Hence, hourly earnings add to the picture of price trends sketched by payrolls and unemployment rates by providing a look back.

Due to the above described differences in the information content of headline figures one would expect that surprises in any of the three headline figures contribute to the explanation of returns observed after an announcement. Prices in financial markets should adjust immediately to a surprise in any figure to which market participants assign some importance. ${ }^{15}$ This is stated by hypothesis H1.

\section{H1: Informativeness of headline figures}

After an announcement, prices react significantly to non-anticipated information in headline figures. All three headline figures contribute to the explanation of returns.

\subsection{Efficient processing of non-anticipated information}

According to the well-known efficient market hypothesis one would expect that prices adjust immediately to public news arrival if this information is regarded to be important. However, only non-anticipated information can move prices, because in an efficient market prices already reflect widely anticipated events. The unique dissemination procedure of statistical agencies in the US guarantees that macroeconomic

\footnotetext{
${ }^{15}$ We would not be able to say which figure is more important if surprises in some figures are perfectly correlated. However, if this is not the case we can investigate their incremental explanatory power.
} 
reports are released precisely according to the schedule. ${ }^{16}$ Reporters are allowed to analyze the data in advance but they are not allowed to communicate until the official release time. When the phone lines are turned on exactly at 8:30 a.m., headline figures are transmitted almost immediately to traders on the floor as well as other market participants via news agencies. Thus, the most obvious non-anticipated information, i.e. surprises in headline figures should be incorporated into prices within a few minutes (hypothesis H2). The time span until this information is fully incorporated into prices may serve as a measure of market efficiency in terms of the speed of information diffusion.

\section{H2: Immediate price impact of headline information}

In an efficient market prices adjust immediately to non-anticipated information in the widely awaited headline figures. Thus no systematic impact can be found after a few minutes.

Hypotheses H1 and H2 refer to the impact of information arrival on the mean function. The following section deals with the implications for the variance function.

\subsection{The volatility impact of information arrival}

The sharply increased volatility immediately after macroeconomic announcements as well as its persistence is well documented (e.g. Ederington and Lee 1993, Crain and Lee 1995, Fleming and Remolona 1997, 1999a and Franke and Hess 2000a). In order to delineate the impact of macroeconomic announcements on volatility, we

\footnotetext{
${ }^{16}$ See, for example, Ederington and Lee $(1993,1995)$ or Fleming and Remolona (1997, 1999a) for a detailed description of these procedures.
} 
differentiate between four components: (1) the impact of the mere existence of new information, i.e. the baseline volatility time pattern related to the announcement of the employment report, (2) the magnitude of non-anticipated information in this report, i.e. absolute surprises in headline figures, (3) the asymmetric impact of good and bad news on volatility, i.e. signed surprises, and (4) the 're-enforcement' effect of surprises in related headline figure, i.e. whether surprises in newly created jobs (payrolls) and the overall (un)employment rate convey the same message.

The first component captures a volatility increase due to an acceleration of the speed of information diffusion after an announcement. This component accounts for the well-known effect that information arrival is associated with higher trading volume as well as higher volatility (for a comprehensive overview see e.g. Karpoff 1987 or Goodhart and O'Hara 1997). Note that this component does not account for specific details concerning the type of information, the magnitude, or direction of surprises. Hence, it captures the deterministic time pattern of volatility around announcements as a baseline. One argument for a persistently higher volatility after announcements stems from the mixture of distribution hypothesis (Clark 1973, Harris 1987) stating that both volume and volatility are driven by the rate of information arrival. Clusters in news then lead to a positively autocorrelated volatility. Considering that an employment report contains a load of detail information besides the exposed headline figures and assuming that this information is only gradually processed, the mixture of distribution hypothesis provides one explanation for volatility clustering after such a report. A somewhat related argument is provided by the sequential information arrival model (Copeland 1976, 1987) which assumes that not all market participants receive the information at the same time. ${ }^{17}$ Another argument is that

\footnotetext{
${ }^{17}$ This view is supported for example by Dacorogna, Müller, Nagler, Olsen, and Pictet (1993)
} 
even if market participants have the same access to the information at the same time, differences of opinion about its price impact can persist for quite some time (e.g. Varian 1985, Kandel and Pearson 1995, or Harris and Raviv 1993). Market participants may interpret the data differently, either if they have additional private information, different prior beliefs, or if they use different models to evaluate the impact of news. Hypothesis H3 summarizes these arguments:

\section{H3: Baseline volatility after an announcement}

Volatility increases immediately after an employment release and declines only slowly afterwards.

The effect of an employment announcement on the volatility before this event is less clear. On the one hand there is some evidence that trading volume declines before such an announcement. ${ }^{18}$ Then, the well-documented positive volume-volatility relation (see e.g. Karpoff 1987) would suggest that volatility before an announcement is lower. However, a possible counterargument arise from the liquidity of markets. If speculative trading dries out, liquidity trades may have a higher price impact. This would increase volatility before an announcement. ${ }^{19}$ Hypothesis H4 follows the first line of reasoning suggesting a "clam before the storm" effect.

and Müller, Dacorogna, Davé, Olsen, Pictet, and von Weizsäcker (1997) who argue that different market participants have different time horizons to process information and to act upon it. This leads to waves in trading activity and thus to waves in price volatility.

${ }^{18}$ Fleming and Remolona (1999a), for example, report that trading volume in U.S. Treasuries is slightly but insignificantly lower before an announcement. Franke and Hess (2000a) find that Bund future trading volume is significantly lower in the five minute interval preceding 8:30 announcements and insignificantly lower before releases scheduled at 9:15 and 10:00 ET.

${ }^{19}$ See, for example, Franke and Hess (2000a). 


\section{H4: Baseline volatility before an announcement}

Volatility is depressed before an announcement.

The second component in the variance specification accounts for the magnitude of non-anticipated information in a report, measured by the deviation of announced headline figures from analysts' 'consensus' forecasts. It seems to be unclear why large surprises should lead to higher volatility, especially if one controls for the direct impact of surprises on the mean function. Since these surprises have a high visibility, i.e. market participants get the information very fast via news vendors such as Bloomberg or Reuters, one would expect an immediate and consistent price reaction rather than a prolonged stage of random fluctuations. One explanation for a persistently high volatility could be that a surprise in a headline figure increases the probability that there are also surprises in other less exposed figures and that it is not easy for market participants to find out what else might be affected. Therefore market participants may have more difficulties in assessing the precise price impact of larger surprises. In addition, surprises leave more room for differences of opinion if one considers the possibility of imprecise measurements. For example, it may be unclear whether a surprise is due to a measurement error, i.e. market participants may disagree about the precision of the signal. Extreme surprises may even call the reliability of forecast models in question. This is stated by hypothesis H5.

\section{H5: Volatility impact of the magnitude of surprises}

Larger surprises give rise to more pronounced differences of opinion. Hence, volatility increases with the magnitude of surprises.

The third volatility component allows to investigate whether 'good' and 'bad' news 
have a different impact on volatility (hypothesis H6). On the basis of daily data Li and Engle (1998), for example, report strong asymmetric effects of scheduled announcements. They find that positive shocks depress volatility on consecutive days and vice versa. While Li and Engle define 'good' and 'bad' news on the basis of the observed daily return reactions, in this study the sign of analysts' forecast errors in the headline figures is exploited directly to asses whether a surprise provides 'good' or 'bad' news. ${ }^{20}$ Therefore, asymmetric effects can be investigated for each of the headline figures separately.

\section{H6: Asymmetric volatility impact of surprises}

Traders' uncertainty, and thus volatility, is higher for 'bad' news than for 'good' news.

The fourth volatility component is included in order to investigate a possible interaction between surprises in headline figures in more detail. Recall that both the nonfarm payrolls figure and the (un)employment rate may indicate future price pressures arising from a tight labor market. Since these two figures are closely related, market participants can use them to cross-validate each other. If both headline figures convey the same message, e.g. a surprisingly high increase in nonfarm payrolls and a lower than expected unemployment rate, the room for differences of opinion about a tight labor market is reduced. A large surprise in one headline figure might be interpreted as a measurement error. If large surprises in both figures occur which point into the same direction, then the possibility of a measurement error is rather

\footnotetext{
${ }^{20} \mathrm{Li}$ and Engle (1998) define, for example, 'big negative news' as news corresponding with (daily) returns lower than $33 \%$ quantile. In contrast, here, 'bad' news is given by a higher than expected nonfarm payrolls figure $\left(S 1^{+}\right)$, a lower than predicted unemployment rate $\left(S 2^{-}\right)$, and a higher than forecasted average hourly earnings announcement $\left(S 3^{+}\right)$.
} 
reduced. In this case, one would expect a sharp initial price reaction, but on the other hand volatility afterwards should be comparatively low. In other words, we should observe a more moderate increase in volatility if large surprises in nonfarm payrolls and the unemployment rate cross-validate each other. ${ }^{21}$ Hence, the fourth component examines whether multiple surprises pointing into the same direction reduce the room for differences of opinion (hypothesis H7).

\section{H7: Re-enforcement effect of surprises in related figures}

Volatility is lower if large surprises in the related nonfarm payrolls figure and the unemployment rate mutually confirm their messages, i.e. if both provide either 'good' or 'bad' news, since then less room is left for differences of opinion. Moreover, this effect is more pronounced for negative surprises given the existence of asymmetric effects (H6)

\section{Empirical analysis}

\subsection{Data}

We analyze Chicago Board of Trade (CBOT) T-bond futures returns in 2-minute intervals during a 90-minute window around employment releases, more precisely from 8:22 to 9:52 a.m. ET (Eastern time). This windows is suggested on the one hand by the floor trading hours of the CBOT which start at 8:20 a.m., ${ }^{22}$ on the other hand by the release of other macroeconomic announcements at 10:00 a.m. Log returns are calculated on the basis of the last trading price observed in a given 2-minute interval.

\footnotetext{
${ }^{21}$ A 'large' surprise will be defined as a surprise exceeding one standard deviation.

${ }^{22}$ The definition of 2-minute returns does not allow to calculate a return for the 8:20-8:22 interval since no price is observed before 8:20.
} 
For example, the return associated with the employment release, i.e. the 8:30-8:32 return, is computed from the last price before the 8:30 announcement and the last price before 8:32. We only use those Fridays on which no other macroeconomic report is released during the 90-minute period. Using a five-year sample, i.e. January 1995 to December 1999, we obtain 53 trading days. ${ }^{23}$ Since the employment report is released almost always on Fridays, we do not have to account for day-of-the-week effects. ${ }^{24}$ CBOT T-Bond futures data are obtained from the Futures Industry Institute. These are 'tick-by-tick' data containing a time-stamped record whenever a price change is observed. Transaction volumes are not recorded. Like in previous studies, the front month contract is analyzed, i.e. the most actively traded contract among the nearby and second nearby contract. ${ }^{25}$ As an illustration for the impact of announcements, the $1 \%$ and $99 \%$ as well as the $5 \%$ and $95 \%$ fractiles of 2 -minute log returns are shown in figure 1.

[insert figure 1 around here]

In order to explore the effect of the bid-ask bounce on the results, some experiments are conducted using log returns computed on the basis of so-called 'pseudo equilibrium prices' as suggested by Ederington and Lee (1995). These are obtained as the average of the last two prices in an interval. However, the results do not change

\footnotetext{
${ }^{23} 7$ trading days are removed at which either leading indicators, personal income, or gross domestic product were released at the same time.

${ }^{24}$ Typically, the employment report is released on the first Friday after the end of the month it refers to. During the sample period 3 reports were announced on a Thursday since the first Friday was a holiday. Moreover, controlling for the impact of announcements Li and Engle (1998) do not find a significant difference between Thursdays and Fridays. This is in line with the findings of Ederington and Lee (1993), Franke and Hess (2000a), and others suggesting that most of the day-of-week and time-of-the-day effects in bond markets can be explained by the announcement schedule.

${ }^{25}$ See, for example, Ederington and Lee (1995) or Franke and Hess (2000a).
} 
in any meaningful aspect using 'pseudo equilibrium prices'. Neither coefficients in the mean nor in the variance function are affected substantially. Although this is somewhat in contrast to the results reported by Ederington and Lee (1995), it is not surprising since a higher aggregation level is used. The influence of the bid-ask spread on returns in very narrow ten-seconds intervals is much more pronounced since price changes are much smaller as compared to 2 -min intervals. ${ }^{26}$ In addition, there seems to be a trade-off between the bias induced by the bid-ask spread, and the bias induced by averaging over lagged prices especially during periods of dense information arrival.

In order to evaluate the impact of non-anticipated information, data on analysts' forecasts in three headline figures are used, i.e. changes in nonfarm payrolls, unemployment rates, and average hourly earnings. Consensus forecasts, i.e. median analysts' forecasts, of headline figures were generously provided by Standard \& Poors Global Markets (MMS). Initially released non-revised figures were extracted from the original monthly BLS releases. Surprises are defined as the difference between initially announced figures and the median analysts' forecast. To facilitate a comparison between the headline figures standardized surprises are used, i.e. for each headline surprises are divided by the sample standard deviation of surprises.

\footnotetext{
${ }^{26}$ The impact of the bid-ask spread depends on the size of the bid-ask bounce relative to average (absolute) price changes in a given interval. 2-min intervals seem to be enough to eliminate the influence of the bid-ask spread largely.
} 


\subsection{Specification of the mean function}

Let $r_{t}$ denote the 2 -minute $\log$ return associated with the interval $t, t=1, \ldots, T$. As mentioned above, the mean function of $r_{t}$ (eq. 1) is modelled as

$$
r_{t}=x_{t}^{\prime} \beta+\epsilon_{t}, \quad \epsilon_{t}=u_{t} \sigma_{t}, \quad u_{t} \sim N(0,1),
$$

where $x_{t}$ denotes the vector of explanatory variables and $\beta$ the corresponding coefficient vector. The (conditional) variance function $\sigma_{t}$ is not explicitly specified yet. Here it is assumed to be time-invariant, i.e. $\sigma_{t}=\sigma$.

The response of the price process to the announcement of the above described three headline figures in the employment report is analyzed based on explanatory variables capturing surprises in each figure. Surprises in the three headline figures nonfarm payrolls, unemployment rates, and hourly earnings are denoted by $S 1, S 2$, and $S 3$, respectively. In addition, time dummies are defined which take on the value 1 for a given interval and zero else, i.e.

$$
D_{\tau}= \begin{cases}1 & \text { if } t=\tau \\ 0 & \text { else }\end{cases}
$$

where $t=1, \ldots, 45$ denotes the 2-minute intervals between 8:22 a.m. and 9:52 a.m. Moreover, surprise dummies are defined for each 2-minute time interval such that the surprise variables interact multiplicatively with the dummy variables, i.e.

$$
S_{\tau}=D_{\tau} S, \quad \text { with } S \in\{S 1, S 2, S 3\}
$$

For example, the interaction term $S 2_{8: 32-8: 34}=D_{8: 32-8: 34} \times S 2$ captures the impact of a surprise in headline 2 on the return in the interval 8:32-8:34. In addition, lagged 2-minute log returns are included in the regressions. 
In a first step, we focus on first moments and analyze the impact of the different types of information separately by running simple OLS regressions of 2-minute log returns on different sets of the corresponding surprise variables. In all regressions the above defined dummy variables cover the interval from 8:28 a.m. to 8:36 a.m. ${ }^{27}$

[insert table 1 around here]

As a benchmark, the first regression, i.e. specification (1) in table 1, includes only a constant as well as lagged returns. The second regression (spec. 2) includes only variables capturing detailed information concerning the first headline figure, i.e. nonfarm payrolls $(S 1)$. The following findings can be summarized:

First, the estimated coefficients provide evidence for a significant impact of the surprise on the price, i.e. the higher the difference between the announced number and the corresponding forecast, the stronger the resulting decline of the price. ${ }^{28}$ The strikingly high coefficient (in absolute terms) of the 8:30-8:32 surprise dummy $\left(S 1_{8: 30-8: 32}\right)$ supports hypothesis $\mathrm{H} 1$ that the arrival of non-anticipated information causes sharp price reactions.

Second, focusing on the time pattern of the price response induced by the payrolls surprise we find significant price movements between two minutes before $\left(S 1_{8: 28-8: 30}\right)$ and four minutes after the announcement $\left(S 1_{8: 30-8: 32}, S 1_{8: 32-8: 34}\right)$. The significant price reaction in the 8:28 to 8:30 interval provides some evidence for slight leakage

\footnotetext{
${ }^{27}$ We also included dummies capturing further intervals before and after the announcement but did not find any significant impacts.

${ }^{28}$ Note that a higher than expected outcome of nonfarm payrolls as well as of hourly earnings is 'bad news' and should lead to an increase in interest rates and a decline in T-bond futures prices. In contrast, a lower than expected unemployment rate is also seen to be 'bad news' for T-bond futures.
} 
effects. This result is quite surprising since strict lock-up conditions should rule out any leakage of information. ${ }^{29}$ However, the largest price reaction is observed within the 8:30-8:32 interval. This reaction sharply declines between 8:32-8:34 and disappears within the following 2-minute interval. These results indicate that the T-bond futures market rapidly advances towards a new equilibrium level after the arrival of non-anticipated information. Thus, the finding of a high speed of information diffusion strongly supports hypothesis H2.

The above described analysis is repeated for the remaining two headline figures, i.e. the unemployment rate $S 2$ and hourly earnings $S 3$. Regression results are given in columns (3) and (4) of table 1. Again, surprises in these headline figures cause strong price responses within the 8:30-8:32 interval coinciding with the announcement, although the reaction to surprises in hourly earnings seems to be slightly less significant (at the 10\% level). Note, however, that the significance of this headline figure is increased if the other figures are included, too (column 5). After 8:32 no statistically significant influence of other figures than nonfarm payrolls is found. Hence, non-anticipated information associated with the unemployment rate and hourly earnings seems to be processed even more rapidly. The adjustment is basically completed within two minutes after the release. Moreover, note that the signs of the estimated coefficients support the hypothesized price reactions. T-bond futures prices rise in response to 'good' news from the inflation front, i.e. a lower than expected increase in nonfarm payrolls, a higher than expected unemployment rate, and a lower than expected average hourly earnings figure.

In regressions (5) and (6) the joint impact of the different types of non-anticipated

\footnotetext{
${ }^{29}$ However, note that if we model the mean and the variance simultaneously, the significance of this effect is reduced. See the results provided in the following section.
} 
information is evaluated. A very important result is that the estimated coefficients remain relatively stable when additional explanatory variables, i.e. surprises in the other headline figures, are included. In general, the significance of the variables is nearly unchanged which illustrates the robustness of the results. These findings indicate that each of the different types of non-anticipated information contributes to the explanation of the return process which provides strong evidence in favor of hypothesis H1. Thus, market participants do not only assign weight to nonfarm payrolls but also pay attention to unemployment rates and hourly earnings.

In order to achieve a more parsimonious representation of the mean function, in regression (6) only those surprise variables are included which turned out to be significant in the previous regressions. Note that virtually no change in the estimated coefficients is recorded. In addition, one lagged return is included.

An interesting issue is the relative importance of the individual headline figures. Therefore, the explanatory power of these components is evaluated on the basis of the coefficient of explained variation $R^{2}$ by regressing the 2-minute log returns on the predictions given by the individual models (1 to 6) via OLS. Results of this estimation are given in last two lines of table 1, i.e. an F-test (zero intercept and slope one) as well as the resulting $R^{2}$. The $\mathrm{F}$ statistics $\left(F_{\alpha_{0}=0, \alpha_{1}=1}\right)$ on $H_{0}: \alpha_{0}=0, \alpha_{1}=1$ are based on the regressions $r_{t}=\alpha_{0}+\alpha_{1} \hat{r}_{t}$, where $\hat{r}_{t}$ denotes the predictions obtained from a given model. For all the regressions, the F statistics are virtually zero due to the fact that $\alpha_{0}$ s and $\alpha_{1}$ s are very close to 0 and 1, respectively. Hence, none of the models yields biased predictions.

The analysis of the predictive power of the models yields some interesting insights: First, accounting for autocorrelation in returns without including surprise variables 
(column 1) explains virtually nothing $\left(R^{2}=0.1 \%\right)$. Second, including surprise variables results in a substantial increase of the explained variation of returns. The inclusion of nonfarm payroll information yields the largest increase in explanatory power which confirms hypothesis H1. In particular, including the surprise dummies based on announced payrolls $15.3 \%$ of the total variation can be explained while with unemployment information 'only' $13.7 \%$ and with average hourly earnings $5.4 \%$ can be explained. The employment release is often referred to as 'the king of announcements'. ${ }^{30}$ The results of these regressions suggest that the nonfarm payroll component 'wields the scepter'. Nevertheless, hourly earnings which is often neglected still has some explanatory power. Third, including all three headline figures (model 5) explains $30.7 \%$ of the total variation which is a quite satisfying result for an intraday return process. The strongly reduced model which includes only the significant variables (column 6) explains $30.5 \%$ of the variation. ${ }^{31}$ This confirms that the insignificant variables of the previous specifications explain almost nothing.

\subsection{Specification of the variance function}

Besides the analysis of the price impact a further main issue in this paper is the investigation of the variance impact of the arrival of non-anticipated information. To analyze the time pattern of the volatility response we use an ARCH specification with multiplicative heteroscedasticity. While in the previous section the variance $\sigma_{t}^{2}$ was assumed to be time-invariant, now it is modelled as (eq. 2)

$$
\sigma_{t}^{2}=\phi \epsilon_{t-1}^{2}+\exp \left(w_{t}^{\prime} \gamma\right)
$$

\footnotetext{
${ }^{30}$ See, for example, Li and Engle (1998) or Andersen and Bollerslev (1998).

${ }^{31} \mathrm{~A}$ constant term and one lag of returns is also included although both variables turned out to be insignificant in most of the other models (1 to 5 ).
} 
where $w_{t}$ is a vector of explanatory variables entering the variance specification collectively as multiplicative heteroscedasticity. Note that $w_{t}$ includes a constant term. $\gamma$ is the corresponding coefficient vector. This specification allows to model the direct impact of explanatory variables on the variance. Since we are mainly interested in the variance response due to surprise effects and not in the volatility persistence and long memory effects, only three ARCH terms are included. No GARCH term is included. ${ }^{32}$

In order to separate the effects of news arrival on the mean and the variance function, first, we model the mean function by a constant term

$$
r_{t}=\beta_{0}+\epsilon_{t}
$$

Estimation results for the corresponding ARCH models are given in table 2. This facilitates a comparison with the previous literature.

[insert table 2 around here]

Second, using a completely specified mean function (eq. 1) allows us to analyze the simultaneous impact of surprises on first and second moments. In particular, we use the mean specification of column (6) in table 1. Estimation results are given in table 3.

[insert table 3 around here]

As a starting point, a simple $\mathrm{ARCH}(3)$ specification is given in column (1) of tables 2 and 3. It illustrates the existence of significant serial dependencies in the variance

\footnotetext{
${ }^{32}$ The implementation of a GARCH effect would lead to an inclusion of the explanatory variables in the model dynamics which would complicate the interpretation of results.
} 
function. Interestingly, the ARCH effect is more pronounced with the fully specified mean function. The $\mathrm{ARCH}(1)$ coefficient turns out to be 0.296 assuming a constant mean function (table 2), and 0.521 for the completely specified mean function (table $3)$. Note that for all the models the significance of the $\operatorname{ARCH}(2)$ coefficients is substantially lower and the $\operatorname{ARCH}(3)$ term is insignificant. Furthermore, as additional explanatory variables are added, in particular the dummies capturing the deterministic pattern of the variance around announcements, the magnitude of the $\mathrm{ARCH}(1)$ coefficient is substantially reduced (below 0.1), although it remains significant at the $1 \%$ level.

Columns (2) to (6) show the results of an ARCH model with multiplicative heteroscedasticity. The model given in column (2) accounts for the deterministic pattern of volatility by including a set of time dummies covering the period from 8:26 a.m. to 9:40 a.m. Note that the base category is the time before the announcement (8:22-8:26) and the last 12 minutes of the analyzed time interval (9:40-9:52). This categorization is quite reasonable as it allows us to analyze the variance response due to announcement effects compared with the variance level before and a longer time after the announcement. The variance peaks in the interval just after the announcement (8:30-8:32) and declines almost monotonically until about one hour after the event. After this period we do not find significant differences compared to the volatility level of the base category. Since the explanatory variables enter the variance equation exponentially, at its peak between 8:30 and 8:32, the variance is more than 50 times higher than the variance in the base period while it drops to a factor of around 9 in the following interval. 30 minutes after the announcement, the variance is just about twice as high as in the base period. Thus, we find an extreme volatility response immediately after the announcement followed by a rela- 
tively strong decline within the first minutes and a more slowly decaying structure a longer time after the news arrival. Hence, these findings strongly support hypothesis H3.

Furthermore, some empirical evidence is obtained that volatility starts to rise between 8:26 to 8:28 and shows a strong increase just before the announcement. Therefore, hypothesis H4 is clearly rejected. The detection of a pre-announcement surge in volatility is in line with the results of Ederington and Lee (1996), Fleming and Remolona (1999a), Franke and Hess (2000a), and others. A further important finding is a significant decrease of the ARCH coefficient compared to specification (1) which indicates that the volatility response due to the arrival of non-anticipated information seems to be a major source of autocorrelation in the volatility process.

In regressions (3) and (4) both variables accounting for the deterministic time pattern and surprise variables are included. In column (3) variables capturing the magnitude of surprises in the three headline figures are added, i.e. absolute surprises $(|S 1|,|S 2|$, and $|S 3|)$. Column (4) allows to investigate asymmetric effects by adding signed surprises $(S 1, S 2$, and $S 3)$. Interestingly, only the nonfarm payrolls and average hourly earnings seem to have a significant impact on the variance. Note, however, that also $|S 2|$ is found to be significant when additional variables enter the variance specification. Nevertheless, a stable result is that a large surprise leads to higher variance (column 3). In addition, the results in column (4) suggest a significant positive impact of 'bad' news for $S 1$ and $S 3 .{ }^{33}$ No significant asymmetric influence is found for $S 2$. Note that while the significance of the results is increased when additional variables enter the variance specification, the structure of these results

\footnotetext{
${ }^{33}$ Recall that positive surprises in $S 1$ and $S 3$ cause negative price movements. In contrast, negative price movements are caused by negative surprises in $S 2$.
} 
remains stable. In connection with the specifications explained below, these results strongly support both hypotheses H5 and H6.

The model in column (5) includes both types of surprise variables. Note that these variables enter the variance specification multiplicatively, i.e. the surprise variables interact with the complete set of time dummies leading to proportional downward or upward shifts of the variance function. For all three type of surprise variables we find a significantly positive impact on the variance. Thus, the higher the surprise in absolute terms, the higher the resulting volatility. Again, this is in accordance with hypothesis H5. Furthermore, the preliminary results of model (3) and (4) are confirmed. We obtain empirical evidence for the existence of asymmetric effects for surprises in nonfarm payrolls and hourly earnings. In particular, positive surprises, i.e. negative shocks for the price process increase the volatility while negative surprises depress the volatility. ${ }^{34}$

Finally, model (6) includes two interaction terms between surprises in nonfarm payrolls and unemployment rates in order to test for the re-enforcement effect stated by hypothesis H7. $I^{S 1^{++} S 2^{--}}$takes on the value one if a large positive value for $S 1$ and at the same time a large negative value for $S 2$ is observed and zero else. Here, large is defined as exceeding one standard deviation. This dummy variable is interacted with the time dummies, creating a separate variable for the interval 8:30 to 8:38 in which volatility is extremely high, i.e. $I_{8: 30-8: 38}^{S 1^{++} S 2^{--}}$, and another variable for the subsequent phase of rather moderately increased volatility, i.e. $I_{8: 38-9: 20}^{S 1^{++} S 2^{--}}$. As hypothesized by H7, a strong and highly significant reduction of volatility is found if both headline

\footnotetext{
${ }^{34}$ Similar asymmetric effects associated with scheduled announcements have also been found by Li and Engle (1998) based on daily data. However, Li and Engle define 'negative' news indirectly on the basis of the observed price reaction rather than including the signed surprise.
} 
figures convey extremely bad news and thus mutually reconfirm their messages. We also analyzed positive re-enforcement effects, i.e. extremely 'good' news in the two headline figures, but these did not turn out to be significant. This result is in line with the findings of asymmetric effects. In general, differences of opinion seem to be more widespread inducing a larger increase in volatility when larger surprises are observed (significantly positive $|S 1|,|S 2|$, and $|S 3|$ coefficients) and when the news is 'bad' rather than 'good' (significantly positive $S 1, S 3$, and insignificantly negative $S 2$ coefficients). However, the room for differences in opinion seems to be significantly reduced if reconfirmation of bad news reduces the possibility of a measurement errors. Then volatility is substantially reduced (significantly negative $I_{8: 30-8: 38}^{S 1^{++} S 2^{--}}$and $I_{8: 38-9: 20}^{S 1^{++} S 2^{--}}$coefficients). This provides strong evidence in favor of H7. In order to evaluate the explanatory power of the different volatility specifications, again their predictive performance is investigated on the basis of OLS regressions of observed values on predicted values. In particular, the squared residuals $\hat{\epsilon}_{t}^{2}$ are regressed on the corresponding volatility forecasts $\hat{\sigma}_{t}^{2}$. Also in this framework a good prediction is indicated by a high $R^{2}$ while the coefficient related to the explanatory variable $\hat{\sigma}_{t}^{2}$ should equal one and the corresponding constant should be zero. The corresponding $\mathrm{F}$ statistics as well as the $R^{2} \mathrm{~s}$ are given in the last two lines of tables 2 and 3.

Comparing the explanatory power of specifications (1) and (2) shows that the predictive performance increases substantially when explanatory variables capturing the volatility response due to the announcement schedule are included. The basic ARCH model provides rather poor results ( $1 \%$ with a constant mean function, table 2 , and $6.4 \%$ with a fully specified mean function, table 3 ). A huge increase of 
the explanatory power is observed when the dummies capturing the deterministic time pattern around releases are included (22.1\% and $15.6 \%$, respectively). When surprise variables are included in addition to the deterministic time pattern variables, another strong increase in the explanatory power is observed in the case of a constant mean function (about $11 \%$ to $18 \%$ ). This increase is more moderate in

the case of a fully specified mean function (about $2 \%$ to 6\%). With an incompletely specified mean function models (5) and (6) have almost the same predictive power. However, with a fully specified mean function model (6) clearly outperforms model (5) as well as the other specifications in table 2 .

\section{Conclusions}

This paper scrutinizes the processing of information contained in the U.S. employment report. The impact of non-anticipated information arrival on both first and second moments of the return process is analyzed. This allows some interesting insights into the creation of uncertainty by the release of macroeconomic news.

In contrast to the previous literature which investigates volatility while refraining from including variables to account for surprises into the mean function, we control for the consistent price reaction to non-anticipated information. With a completely specified mean function, the volatility function receives a different interpretation: Rather than capturing just the fluctuations of squared returns, the volatility function describes market participants' uncertainty about the precise price impact of new information, while the mean function describes the shift in average beliefs about the new equilibrium price level induced by the arrival of non-anticipated information.

The main results derived on the basis of this estimation approach are as follows. 
First, surprises in all three headline figures have a distinct impact on the level of prices, the nonfarm payrolls figure has the strongest impact. Second, non-anticipated information leads to an almost instantaneous price reaction which is completed within the first two to four minutes. This indicates that the market advances very rapidly to a new equilibrium price level. Third, volatility is slightly higher before the announcement, maybe due to a temporary illiquidity before the announcement. Volatility surges immediately afterwards. In particular, volatility peaks in the 2minute interval associated with the announcement. Volatility is substantially reduced in the following interval, though remaining elevated for about one hour. The high volatility after the announcement suggests that there is considerable uncertainty about the precise price impact of new information. Forth, strong magnitude effects of surprises are found to have an impact on volatility, i.e. larger surprises do not only lead to a more pronounced price reaction, they also create more uncertainty. Fifth, there are strong asymmetric effects, i.e. 'bad' news measured in terms of the surprises contained in headline figures raise the volatility substantially while 'good news' reduce traders' uncertainty. This suggests that market participants are particularly upset when negative shocks occur. Last but not least, a strong interaction between headline figures with a related information content is detected. Pointing into the same direction, extremely bad news in the nonfarm payrolls figure re-enforce the signal of a devastating unemployment rate reading. This cross-validation of extreme signals leaves less room for traders' differences of opinion, and hence decreases volatility. 


\section{References}

Andersen, T. G., And T. Bollerslev (1997): "Intraday periodicity and volatility persistence in financial markets," Journal of Empirical Finance, 4, 115-158.

(1998): "Deutsche Mark-Dollar volatility: intraday activity patterns, macroeconomic announcements and longer run dependencies.," Journal of Finance, 53, 219-265.

Balduzzi, P., E. J. Elton, and C. Green (1997): "Economic news and the yield curve: Evidence for the U.S. Treasury market," Discussion paper, New York University, Oktober 1997.

Becker, K. G., J. E. Finnerty, And K. J. Kopecky (1996): "Macroeconomic news and the efficiency of international bond futures markets," Journal of Futures Markets, 16, 131-145.

Berkman, N. G. (1978): "On the significance of weekly changes in M1," New England Economic Review, May-June, 5-22.

Bollerslev, T., J. Cai, and F. M. Song (2000): "Intraday periodicity, long memory volatility, and macroeconomic announcement effects in the US Treasury bond market," Journal of Empirical Finance, 7, 37-55.

Christie-David, R., And M. Chaudhry (1999): "Liquidity and maturity effects around news releases," Journal of Financial Research, 22, 47-67.

Clark, P. K. (1973): "A subordinated stochastic process model with finite variance for speculative prices," Econometrica, 41, 135-155.

Cook, T., And S. Korn (1991): "The reaction of interest rates to the employment report: The role of policy anticipations," Economic Review, Federal Reserve Bank of Richmond, 77, 3-12.

Copeland, T. E. (1976): "A model of asset trading under the assumption of sequential information arrival," Journal of Finance, 31, 1149-1168.

(1987): "The effect of sequential information arrival on asset prices: An experimental study," Journal of Finance, 42, 763-797. 
Crain, S. J., And J. H. LEE (1995): "Intraday volatility in interest rate and foreign exchange spot and futures markets," Journal of Futures Markets, 15, 395-421.

Dacorogna, M. M., U. A. Müller, R. J. Nagler, R. B. Olsen, and O. V. PICTET (1993): "A geographical model for the daily and weekly seasonal volatility in the foreign exchange market," Journal of International Money and Finance, $12,413-43$.

Dominguez, K. M. (1999): "The Market Microstructure of Central Bank Intervention," Discussion Paper W7337, Cambridge, MA.

DWyer, G.-P., AND R. W. HAFER (1989): "Interest rates and economic announcements," Federal Reserve Bank of St. Louis Review, 71, 34-46.

Ederington, L. H., And J. H. LeE (1993): "How markets process information: News releases and volatility," Journal of Finance, 48, 1161-1191.

(1995): "The short-run dynamics of the price adjustment to new information," Journal of Financial and Quantitative Analysis, 31, 117-134.

(1996): "The creation and resolution of market uncertainty: The impact of information releases on implied volatility," Journal of Financial and Quantitative Analysis, 31, 513-539.

EDISON, H. J. (1996): "The reaction of exchange rates and interest rates to news releases," Discussion Paper 570, Board of Governors of the Federal Reserve System.

Fleming, M. J., And E. M. Remolona (1997): "What moves the bond market," Economic Policy Review, Federal Reserve Bank of New York, December, 31-50.

(1999a): "Price formation and liquidity in the U.S. Treasury market: The response to public information," Journal of Finance, 54, 1901-1915.

- (1999b): "The term structure of announcement effects," Discussion paper, Federal Reserve Bank of New York.

Franke, G., AND D. Hess (2000a): "The impact of scheduled news announcements on T-bond and Bund futures trading," in Institutional Arrangements for Global Economic Integration, ed. by H.-J. Vosgerau, pp. 337-366, MacMillan, London. 
- (2000b): "Information diffusion in electronic and floor trading," Journal of Empirical Finance, 7, 455-478.

Goodhart, C. A. E., And M. O'Hara (1997): "High frequency data in financial markets: Issues and applications," Journal of Empirical Finance, 4, 73-114.

Hardouvelis, G. A. (1988): "Economic news, exchange rates, and interest rates," Journal of International Money and Finance, 7, 23-35.

HARRIS, L. (1987): "Transaction data tests of the mixture of distributions hypothesis," Journal of Financial and Quantitative Analysis, 22, 127-141.

Harris, M., AND A. Raviv (1993): "Difference of opinion make a horse race," Review of Financial Studies, 6, 473-506.

Harvey, C. R., And R. D. Huang (1991): "Volatility in the foreign currency futures market," Review of Financial Studies, 4, 543-569.

Hess, D. (2001): "Surprises in U.S. macroeconomic releases: Determinants of their relative impact on T-Bond futures," Discussion Paper 01/01, Center of Finance and Econometrics, University of Konstanz.

Hess, D., And M. Moersch (2001): "Predictability in analysts' forecast errors: Does discreteness matter?," Working paper, University of Konstanz.

Jones, C. (1998): "The economic sources of long memory in interest rate volatility," Second International Conference on High Frequency Data in Finance, Proceedings, Vol. 2, Olsen and Associates, Zürich.

Jones, C., O. Lamont, and R. Lumsdaine (1998): "Macroeconomic news and bond market volatility," Journal of Financial Economics, 47, 315-337.

Kandel, E., And N. D. Pearson (1995): "Differential interpretation of public signals and trade in speculative markets," Journal of Political Economy, 103, $831-872$.

KARPOFF, J. M. (1987): "The relation between price changes and trading volume: a survey," Journal of Financial and Quantitative Analysis, 22, 109-126.

Lamoureux, C. G., and W. D. Lastrapes (1990): "Heteroskedasticity in stock return data: volume versus GARCH effects," Journal of Finance, 45, 221-229. 
Li, L., And R. F. Engle (1998): "Macroeconomic announcements and volatility of Treasury futures," Discussion paper, Department of Economics, University of California, San Diego Discussion Paper 98-27.

Müller, U. A., M. M. Dacorogna, R. D. Davé, R. B. Olsenn, O. V. Pictet, ANd J. E. von Weizsäcker (1997): "Volatilities of different time resolutions - Analyzing the dynamics of market components," Journal of Empirical Finance, 4, 213-39.

Niemira, M. P., And G. F. Zukowski (1998): Trading the fundamentals: The trader's guide to interpreting economic indicators and monetary policy. McGraw Hill, New York.

PrAG, J. (1994): "The response of interest rates to unemployment rate announcements: Is there a natural rate of unemployment," Journal of Macroeconomics, 16, $171-184$.

Rogers, R. M. (1998): Handbook of key economic indicators. McGraw Hill, New York, 2 edn.

URICh, T., AND P. WAChTEL (1981): "Market response to the weekly money supply announcements in the 1970s," Journal of Finance, 36, 1063-1072.

(1984): "The effects of inflation and money supply announcemnets on interest rates," Journal of Finance, 39, 1177-1188.

VARIAN, H. R. (1985): "Divergence of opinion in complete markets," Journal of Finance, 40, 309-317. 
Figure 1: 2-min returns around employment releases

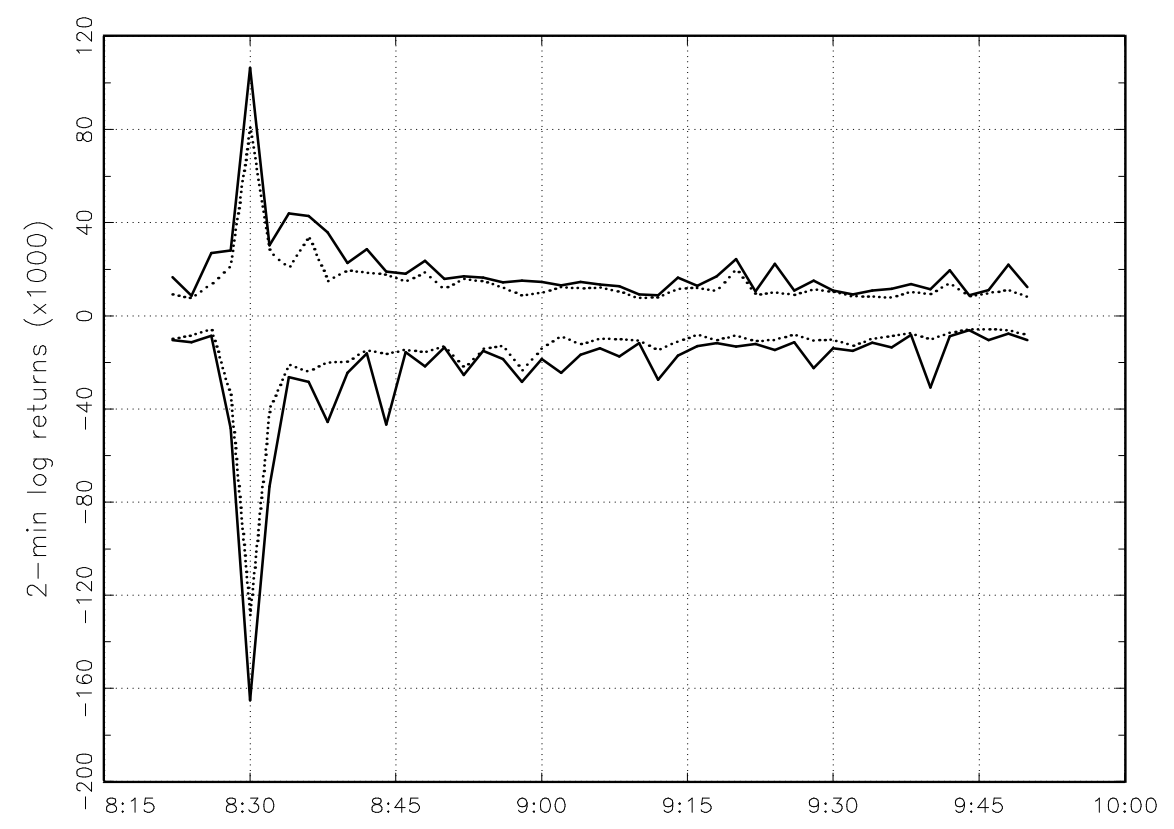

Descriptive statistics of 2-minute log returns (times 10000) during the interval 8:22 to 9:52 a.m. ET at employment announcement days are reported. The sample period is January 1995 to December 1999, resulting in 53 days at which no other macroeconomic report is released along with the employment report. $1 \%$ and $99 \%$ percentiles (solid lines) are displayed as well as $5 \%$ and $95 \%$ percentiles (dotted lines). 
Table 1: Mean function estimates

\begin{tabular}{lcccccc}
\hline & $(1)$ & $(2)$ & $(3)$ & $(4)$ & $(5)$ & $(6)$ \\
\hline const & -0.126 & -0.084 & 0.008 & -0.039 & 0.133 & 0.124 \\
$r_{t-1}$ & -0.027 & $-0.081^{*}$ & -0.035 & -0.024 & $-0.088^{*}$ & -0.073 \\
$S 1_{8: 28-8: 30}$ & & $-3.664^{*}$ & & & $-4.107^{* *}$ & $-3.675^{*}$ \\
$S 1_{8: 30-8: 32}$ & & $-29.006^{* * *}$ & & & $-26.590^{* * *}$ & $-26.528^{* * *}$ \\
$S 1_{8: 32-8: 34}$ & & $-7.310^{* *}$ & & & $-7.528^{* *}$ & $-7.075^{* *}$ \\
$S 1_{8: 34-8: 36}$ & & 0.242 & & & 0.781 & \\
$S 2_{8: 28-8: 30}$ & & & -0.451 & & -1.619 & \\
$S 2_{8: 30-8: 32}$ & & & $26.552^{* * *}$ & & $19.274^{* * *}$ & $19.296^{* * *}$ \\
$S 2_{8: 32-8: 34}$ & & & 1.815 & & 1.164 & \\
$S 2_{8: 34-8: 36}$ & & & 1.165 & & 1.449 & \\
$S 3_{8: 28-8: 30}$ & & & & 1.300 & 0.524 & \\
$S 3_{8: 30-8: 32}$ & & & & $-19.762^{*}$ & $-24.742^{* * *}$ & $-24.748^{* * *}$ \\
$S 3_{8: 32-8: 34}$ & & & & 0.066 & -2.634 & \\
$S 3_{8: 34-8: 36}$ & & & & 0.777 & 0.894 & \\
\hline $\bar{R}^{2}$ & 0.001 & 0.152 & 0.135 & 0.052 & 0.303 & 0.303 \\
regular F-test & 0.360 & $5.446^{* * *}$ & $2.754^{* *}$ & 0.682 & $6.420^{* * *}$ & $12.371^{* * *}$ \\
BCC & -0.004 & 0.009 & 0.009 & 0.009 & 0.036 & 0.013 \\
\hline$F_{\alpha_{0}=0, \alpha_{1}=1}$ & 0.000 & 0.000 & 0.000 & 0.000 & 0.000 & 0.000 \\
$R^{2}$ & 0.001 & 0.153 & 0.137 & 0.054 & 0.307 & 0.305 \\
\hline
\end{tabular}

OLS regressions of 2-minute log returns at employment report announcement days. The sample period is January 1995 to December 1999. 53 days are used at which no other report is announced along with the employment report. For each of these days the intraday interval 8:22-9:52 ET is analyzed. The adjusted coefficient of determination $\left(\bar{R}^{2}\right)$ is given as well as the results of a regular F-test on the hypothesis of a zero coefficient vector. The Schwartz information criterion (BIC) is also provided. In addition, the $R^{2}$ from a regression of observed returns on predicted returns is given along with the results of an F-test on the joint hypothesis of a zero intercept and a unit slope $\left(F_{\alpha_{0}=0, \alpha_{1}=1}\right)$. Inference is based on robust standard errors. 
Table 2: Variance function estimates (assuming a constant mean)

\begin{tabular}{|c|c|c|c|c|c|c|}
\hline & (1) & $(2)$ & (3) & (4) & (5) & (6) \\
\hline $\begin{array}{l}\text { Mean: } \\
\text { const }\end{array}$ & 0.372 & 0.125 & 0.151 & $0.179^{*}$ & $0.178^{*}$ & $0.176^{*}$ \\
\hline $\begin{array}{c}\text { Variance: } \\
\text { const }\end{array}$ & $4.626^{* * *}$ & $3.051^{* * *}$ & $2.489^{* * *}$ & $2.993^{* * *}$ & $2.591^{* * *}$ & $2.542^{* * *}$ \\
\hline$\varepsilon_{t-1}^{2}$ & $0.296^{* *}$ & $0.106^{* * *}$ & $0.094^{* * *}$ & $0.079^{* * *}$ & $0.083^{* * *}$ & $0.081^{* * *}$ \\
\hline$\varepsilon_{t-2}^{2}$ & -0.001 & $0.037^{* *}$ & $0.025^{*}$ & $0.024^{*}$ & $0.021^{*}$ & $0.021 *$ \\
\hline$\varepsilon_{t-3}^{2}$ & 0.006 & 0.028 & 0.020 & 0.024 & 0.019 & 0.014 \\
\hline$D_{8: 26-8: 28}$ & & $0.690^{* *}$ & $0.704^{* *}$ & $0.624^{* *}$ & $0.671^{* *}$ & $0.673^{* *}$ \\
\hline$D_{8: 28-8: 30}$ & & $2.090^{* * *}$ & $2.073^{* * *}$ & $2.052^{* * *}$ & $2.028^{* * *}$ & $2.004^{* * *}$ \\
\hline$D_{8: 30-8: 32}$ & & $4.968^{* * *}$ & $4.802^{* * *}$ & $4.777^{* * *}$ & $4.740^{* * *}$ & $4.799^{* * *}$ \\
\hline$D_{8: 32-8: 34}$ & & $2.197^{* * *}$ & $2.291^{* * *}$ & $2.308^{* * *}$ & $2.352^{* * *}$ & $2.385^{* * *}$ \\
\hline$D_{8: 34-8: 36}$ & & $0.732^{*}$ & $0.975^{* *}$ & $1.035^{* * *}$ & $1.102^{* * *}$ & $1.146^{* * *}$ \\
\hline$D_{8: 36-8: 38}$ & & $2.159^{* * *}$ & $2.258^{* * *}$ & $2.179^{* * *}$ & $2.244^{* * *}$ & $2.276^{* * *}$ \\
\hline$D_{8: 38-8: 40}$ & & $1.671^{* * *}$ & $1.626^{* * *}$ & $1.663^{* * *}$ & $1.667^{* * *}$ & $1.713^{\text {*** }}$ \\
\hline$D_{8: 40-8: 42}$ & & $1.223^{* * *}$ & $1.185^{* * *}$ & $1.249^{* * *}$ & $1.218^{* * *}$ & $1.257^{* * *}$ \\
\hline$D_{8: 42-8: 44}$ & & $1.141^{* * *}$ & $1.155^{* * *}$ & $1.123^{* * *}$ & $1.137^{* * *}$ & $1.185^{* * *}$ \\
\hline$D_{8: 44-8: 50}$ & & $1.287^{* * *}$ & $1.234^{* * *}$ & $1.248^{* * *}$ & $1.249^{* * *}$ & $1.275^{* * *}$ \\
\hline$D_{8: 50-9: 00}$ & & $0.768^{* * *}$ & $0.820^{* * *}$ & $0.756^{* * *}$ & $0.803^{* * *}$ & $0.836^{* * *}$ \\
\hline$D_{9: 00-9: 10}$ & & $0.441^{* * *}$ & $0.489^{* * *}$ & $0.462^{* * *}$ & $0.492^{* * *}$ & $0.543^{* * *}$ \\
\hline$D_{9: 10-9: 20}$ & & $0.348^{* *}$ & $0.386^{* * *}$ & $0.340^{* *}$ & $0.381^{* * *}$ & $0.404^{* * *}$ \\
\hline$D_{9: 20-9: 30}$ & & 0.248 & $0.211^{*}$ & $0.257^{*}$ & $0.222^{*}$ & $0.262^{* *}$ \\
\hline$D_{9: 30-9: 40}$ & & -0.053 & -0.010 & -0.051 & -0.016 & -0.013 \\
\hline$|S 1|$ & & & $0.165^{* *}$ & & $0.168^{* * *}$ & $0.228^{* * *}$ \\
\hline$|S 2|$ & & & $0.099^{*}$ & & $0.088^{*}$ & $0.102^{* *}$ \\
\hline$|S 3|$ & & & $0.475^{* * *}$ & & $0.287^{* * *}$ & $0.278^{* * *}$ \\
\hline$S 1$ & & & & $0.229^{* * *}$ & $0.180^{* * *}$ & $0.219^{* * *}$ \\
\hline$S 2$ & & & & -0.025 & -0.008 & -0.014 \\
\hline$S 3$ & & & & $0.277^{* * *}$ & $0.169^{* * *}$ & $0.168^{* * *}$ \\
\hline$I_{8: 30-8: 38}^{S 1^{++} S 2^{--}}$ & & & & & & $-0.881^{* *}$ \\
\hline $\begin{array}{l}S 1_{8: 40-S: 22^{--}}^{S: 20} \\
\end{array}$ & & & & & & $-0.553^{* *}$ \\
\hline $\mathrm{BIC}$ & 7.644 & 6.828 & 6.799 & 6.803 & 6.796 & 6.800 \\
\hline$F_{\alpha_{0}=0}$ & $8.900^{* * *}$ & 1.296 & 1.752 & $2.305 *$ & $2.633^{*}$ & 2.052 \\
\hline$R^{2}$ & 0.010 & 0.231 & 0.349 & 0.359 & 0.423 & 0.425 \\
\hline
\end{tabular}

Maximum Likelihood estimation of 2-minute log returns at employment report announcement days (sample period: January 1995 to December 1999, i.e. 53 nonoverlapping employment announcement days). For each day the intraday interval 8:22-9:52 ET is analyzed. The Schwartz information criterion (BIC) is given as well as the Ljung-Box statistic for up to 10 lags of standardized squared residuals $\left(Q_{\hat{\varepsilon}_{t} / \hat{\sigma}_{t}^{2}}(10)\right)$. In addition, the $R^{2}$ from a regression of observed squared returns on predicted variances is given along with the results of an F-test on the joint hypothesis of a zero intercept and a unit slope $\left(F_{\alpha_{0}=0, \alpha_{1}=1}\right)$. Inference is based on robust standard errors. 
Table 3: Simultaneous estimation of the mean and variance function

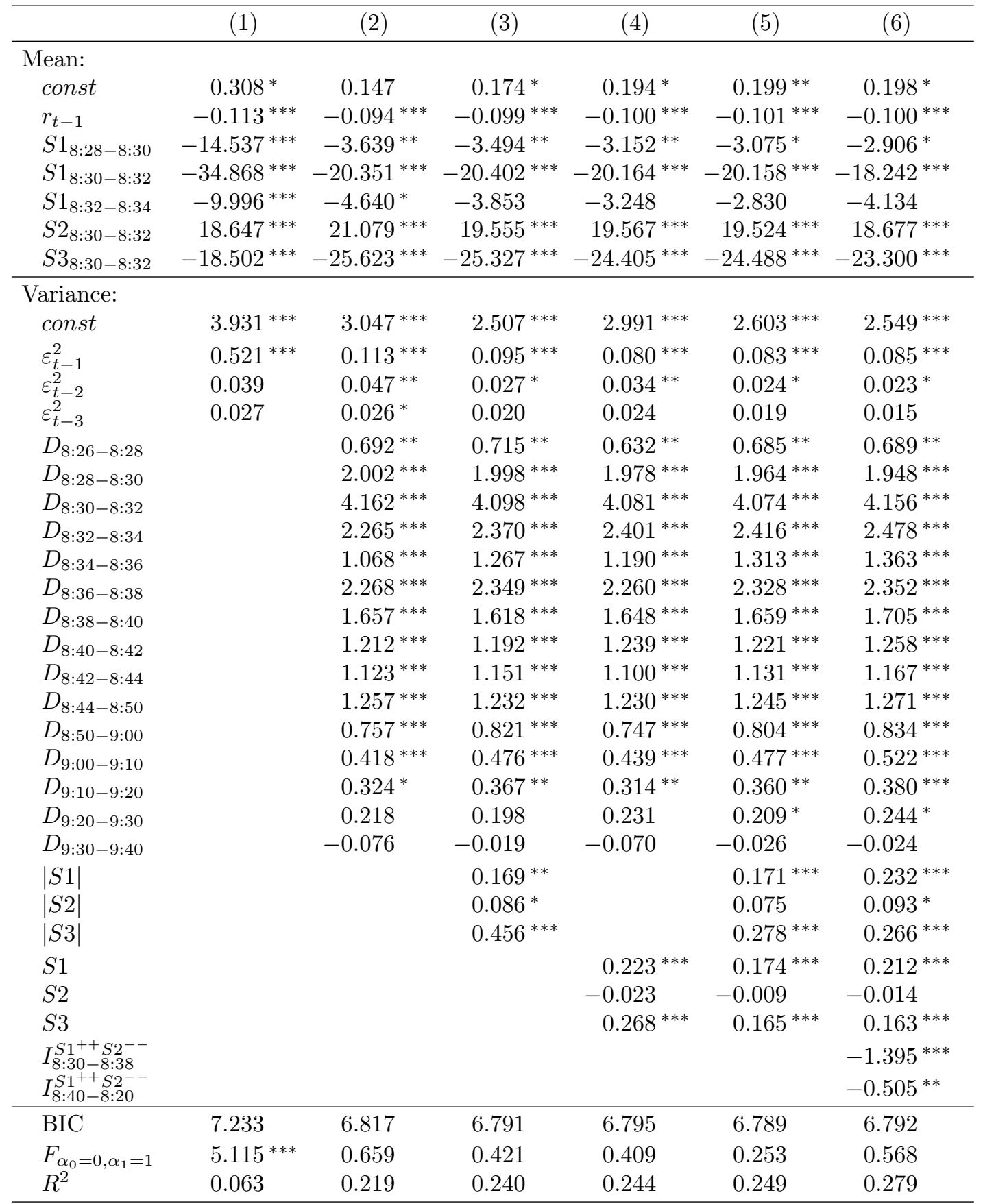

Maximum Likelihood estimation of 2-minute log returns at employment report announcement days. For details see table 2. 